УДК 54-116/661.728.7 667.16

\title{
ИЗМЕНЕНИЕ МОРФОЛОГИЧЕСКИХ ОСОБЕННОСТЕЙ ЦЕЛЛЮЛОЗЫ ПОД ВОЗДЕЙСТВИЕМ ТЕТРАХЛОРИДА ТИТАНА
}

\author{
() Л.А. Кувиинова ${ }^{* 1}$, Т.Н. Манахова \\ ${ }^{1}$ Институт химии Коми научного центра Уральского отделения РАН, \\ ул. Первомайская, 48, Сыктывкар, 167982, Республика Коми (Россия), \\ e-mail:fragl74@mail.ru \\ ${ }^{2}$ Северный (Арктический) федеральный университет, Набережная \\ Северной Двины, 17, Архангельск, 163002 (Россия)
}

Показано изменение морфологических особенностей целлюлозы в результате воздействия на нее растворов тетрахлорида титана с применением автоматического анализатора волокна L\&W Fiber Tester. Установлено, что в зависимости от условий эксперимента происходит снижение средней длины частиц в целлюлозных образцах от 2,20 до 0,16 мм. Выявлены взаимосвязи средней длины и диаметра частиц образцов с величиной средней степени полимеризации $\left(\mathrm{CП}_{\text {ср }}\right)$ целлюлозы и содержанием в них Ti (IV).

Ключевые слова: целлюлоза, порошковая целлюлоза, тетрахлорид титана $\left(\mathrm{TiCl}_{4}\right)$, анализатор волокна, длина и диаметр волокна.

Работа выполнена при финансовой поддержке программы Президиум РАН «Создание и совериенствование методов химического анализа и исследования структуры веществ и материалов» (Проект 12-П-3-1024).

\section{Введение}

Порошковая целлюлоза (ПЦ) вне зависимости от способа получения пользуется большим спросом на мировом рынке. Ее используют во многих отраслях промышленности в качестве самостоятельного продукта, а также как добавку к каким-либо композициям, проявляющую свойства наполнителя, эмульгатора, связующего, сорбента и др. Физико-химические свойства ПЦ, в частности функциональный состав, структурно-морфологические особенности, а также доступность для реагентов ее поверхности, зависящей от размеров и формы получаемых целлюлозных частиц, являются определяющим фактором при выборе направления использования этого продукта в дальнейшем.

Из многочисленных способов возможного получения ПЦ [1-6] наиболее распространенным является гидролитическая обработка целлюлозосодержащего сырья в водных растворах минеральных кислот. Причем неоспоримым преимуществом ПЦ, получаемой этим способом, является имеющаяся на сегодняшний день информация о комплексе ее физико-химических свойств, изучаемых на протяжении уже многих лет с момента появления этого продукта.

Для придания ПЦ новых свойств, существенно отличающих ее от микрокристаллической целлюлозы по степени кристалличности, распределению частиц по размерам, функциональному составу и другим физико-химическим показателям в последние годы разрабатываются другие способы получения этого про-

Кувшинова Лариса Александровна - младший научный сотрудник, тел.: (8212) 21-99-61, e-mail: frag174@ mail.ru Манахова Татьяна Николаевна - аспирант кафедры технологии целлюлозо-бумажной промышленности, тел.: (8182) 65-00-92, e-mail: tatiankaya17@yandex.ru дукта. Один из них основан на применении безводных технологий с использованием различных кислот Льюиса [7-9]. Для сравнительно быстрого разрыва гликозидных связей в целлюлозе, приводящего к снижению ее степени полимеризации, можно ис-

\footnotetext{
* Автор, с которым следует вести переписку.
} 
пользовать $\mathrm{TiCl}_{4}-$ высокоэффективную и мягкодействующую в отношении эфирных связей биополимеров кислоту Льюиса. Воздействие растворов $\mathrm{TiCl}_{4}$ на целлюлозу приводит к модифицированию ее поверхности путем адсорбции титансодержащих соединений [10-12], сопровождающееся деструкцией макромолекул целлюлозы $[11,13]$. В результате этого происходит снижение длины целлюлозного волокна с образованием из него частиц меньшего размера. В зависимости от условий такой обработки можно получить коротковолокнистую, или тонкодисперсную, ПЦ [14].

Изучение распределения фракций целлюлозных частиц по размеру, включая усредненные показатели их фактического диаметра и длины, в зависимости от условий обработки биополимера растворами $\mathrm{TiCl}_{4}$ позволяет выявить закономерности физического изменения волокон, происходящего при получении тонкодисперсной ПЦ указанным способом. Подобного рода результаты, как правило, носят и фундаментальный, и прикладной характер. В практической области такая информация может быть весьма актуальной и значимой, например, для оценки параметров целлюлозного волокна и получаемой на его основе ПЦ, используемой с какой-либо целью в дальнейшем.

Данная работа посвящена изучению влияния растворов $\mathrm{TiCl}_{4}$ на изменение морфологических особенностей волокон целлюлозы.

\section{Экспериментальная часть}

Для работы использовали коммерческий $\mathrm{TiCl}_{4}$, а также гексан $\left(\mathrm{C}_{6} \mathrm{H}_{14}\right)$ фирмы «Вектон» квалификации «ч», которые перед применением очищали простой перегонкой [15].

В качестве объекта исследования использовали продукт производства ОАО «Монди Сыктывкарский ЛПК» с техническим названием «небеленая сульфатная целлюлоза хвойных пород древесины», которая в дальнейшем для упрощения условно будет называться целлюлозой. Она имела следующие характеристики: средняя степень полимеризации (СП ср) 1260 и содержание лигнинной составляющей 5,7\%.

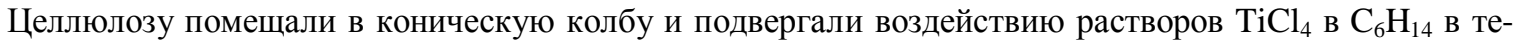
чение 30 мин при $22 \pm 0,1{ }^{\circ} \mathrm{C}$ и $69,9 \pm 0,1^{\circ} \mathrm{C}$, применяя интенсивное перемешивание целлюлозной суспензии. Диапазон рабочих концентраций кислоты Льюиса составил $0 \div 204,1$ ммоль/дм³. После обработки содержимое колбы отфильтровывали, промывали гексаном и далее высушивали до воздушно-сухого состояния при $22 \pm 1^{\circ} \mathrm{C}$.

В полученных целлюлозных образцах определяли содержание Ti (IV) в виде окрашенного комплекса с пероксидом водорода в кислой среде с использованием фотоколориметрического метода анализа [16]. Для десорбции катионов металла из образцов применяли водный раствор серной кислоты с массовой концентрацией $10 \%$.

Величину СП разцов в кадоксене по формуле, приведенной для полидисперсных целлюлоз [17].

Характеристики волокон целлюлозы до и после воздействия кислоты Льюиса определяли на автоматическом анализаторе волокна L\&W Fiber Tester.

\section{Обсуждение результатов}

Образцы целлюлозы, обработанные растворами $\mathrm{TiCl}_{4}$ в $\mathrm{C}_{6} \mathrm{H}_{14}$ различных концентраций, отличаются

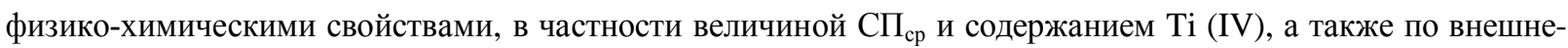
му виду и размерам частиц. В таблице представлены условия получения образцов и их физико-химические характеристики.

Для оценки влияния концентрации растворов $\mathrm{TiCl}_{4}$ на длину и диаметр целлюлозных частиц, образовавшихся в результате деструкции волокон целлюлозы, представленные в таблице образцы проанализированы на приборе L\&W Fiber Tester в виде водных суспензий. На рисунке 1 показано распределение длины целлюлозных частиц образцов 1 и 2 (см. табл.) по фракциям. Хвойная целлюлоза до обработки кислотой Льюиса отличается значительной полидисперсностью по длине волокон, кривая их распределения носит бимодальный характер. Применение раствора $\mathrm{TiCl}_{4}$ минимальной концентрации 3,8 ммоль/дм ${ }^{3}$ приводит к смещению одного из пиков исходной целлюлозы, соответствующего диапазону длин волокон $2,5 \div 3,0$ мм, в сторону с более низкими значениями длины $(0,5 \div 1,0$ мм), при этом происходит увеличение доли этой фракции 2,6 раза. 
Условия обработки целлюлозы и физико-химические характеристики получаемых образцов

\begin{tabular}{c|c|c|c|c|c|c}
\hline \multirow{2}{*}{ № } & \multicolumn{3}{|c|}{ Условия обработки } & Содержание Ti (IV), & \multirow{2}{*}{ СП } \\
п/п & $\begin{array}{c}\text { Растворимая } \\
\text { фракция*, } \%\end{array}$ \\
\cline { 2 - 4 } & Этапы обработки & $\mathrm{t},{ }^{\circ} \mathrm{C}$ & $\mathrm{C}\left(\mathrm{TiCl}_{4}\right)$, ммоль/дм ${ }^{3}$ & 0 & 1260 & 1,94 \\
2 & - & - & 0 & 0,11 & 520 & 8,15 \\
2 & $\mathrm{TiCl}_{4}-\mathrm{C}_{6} \mathrm{H}_{14}$ & 22 & 3,8 & 0,58 & 160 & 15,77 \\
4 & $\mathrm{TiCl}_{4}-\mathrm{C}_{6} \mathrm{H}_{14}$ & 22 & 33,3 & 0,93 & 140 & 21,14 \\
5 & $\mathrm{TiCl}_{4}-\mathrm{C}_{6} \mathrm{H}_{14}$ & 22 & 78,0 & 1,49 & 140 & 25,32 \\
& $\mathrm{TiCl}_{4}-\mathrm{C}_{6} \mathrm{H}_{14}$ & 69,9 & 204,1 & 0,58 & 160 & 15,77 \\
$6^{* * *}$ & $\mathrm{TiCl}_{4}-\mathrm{C}_{6} \mathrm{H}_{14}$ & 22 & 33,3 & - & 190 & - \\
& Десорбция в $\mathrm{H}_{2} \mathrm{SO}_{4}$ & 22 & - & 0,53 & 130 & 13,35 \\
\hline
\end{tabular}

* растворимую фракцию определяли по разнице массы образцов до и после воздействия водного 10\%-ного раствора $\mathrm{H}_{2} \mathrm{SO}_{4}$, применяемого для десорбции Ti (IV).

** образец 6 получен в результате последовательных двукратных обработок, разделенных процессом десорбции Ti (IV).

Рис. 1. Фракционное распределение длины волокон целлюлозы до (1) и после (2) воздействия раствора $\mathrm{TiCl}_{4}$ концентрацией 3,8 ммоль/дм ${ }^{3}$

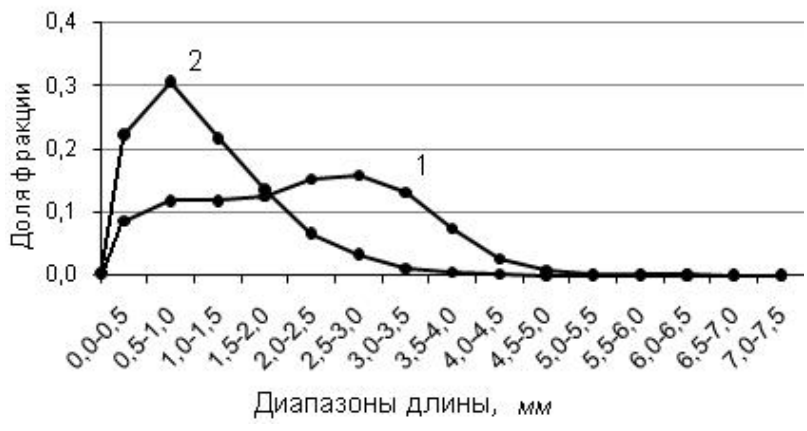

Обработка целлюлозы растворами $\mathrm{TiCl}_{4}$ различных концентраций приводит к унимодальному распределению целлюлозных частиц по длине. С увеличением концентрации растворов кислоты Льюиса от 3,8 до 204,1 ммоль/дм³ происходит снижение величины СП ср целлюлозы в образцах 2-5 (см. табл.) от 520

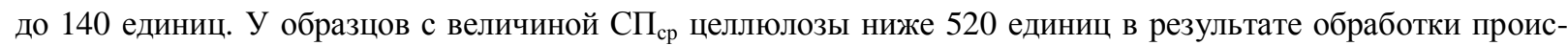
ходит повышение доли фракции с длиной целлюлозных частиц $0,12 \div 0,15$ мм. Наблюдаемая тенденция показана на рисунке 2 в виде гистограммы.

Образец 6, полученный в условиях последовательной двухкратной (разделенной процессом десорбции Ti (IV)) обработки целлюлозы растворами $\mathrm{TiCl}_{4}$ одинаковой концентрации, характеризуется наименьшей величиной $\mathrm{CП}_{\mathrm{p}}$, равной 130 единицам, и наиболее узким распределением целлюлозных частиц по длине с преобладанием фракции с длиной частиц $0,12 \div 0,15$ мм.

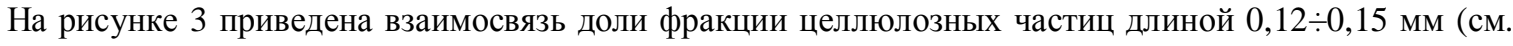
рис. 2), постепенно увеличивающейся в результате деструкции волокон целлюлозы, и величины СП люлозы в образцах.

Линейная взаимосвязь величины СП цр целлюлозы в образцах и их средней длины показана на рисунке 4. Из которого видно, что средняя длина исходной целлюлозы в результате деструкции ее волокон

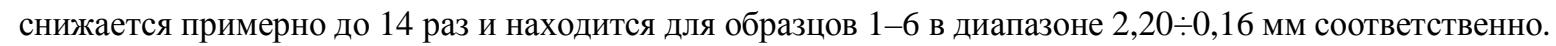

$\mathrm{B}$ процессе обработки целлюлозы в растворах $\mathrm{TiCl}_{4}$ на поверхности целлюлозных волокон происходит адсорбция титансодержащих групп (см. табл.), по мере увеличения содержания которых диаметр волокна также претерпевает изменения. На рисунке 5 видно, что средний диаметр волокна целлюлозы (равный до обработки 28,8 мкм) увеличивается прямо пропорционально содержанию на его поверхности Ti (IV), максимальная величина этого показателя составляет 33,6 мкм при 1,49 ммоль Ti (IV) в 1 г образца.

Постепенное накапливание титансодержащих групп в процессе обработки целлюлозы может приводить к последующему разрушению на поверхности волокна (в аморфных и аморфно-кристаллических участках) водородных связей, доступных для воздействия $\mathrm{TiCl}_{4} \mathrm{~B}_{6} \mathrm{H}_{14}$. Гексан при этом играет роль не только растворителя для кислоты Льюиса, но и является инклюдирующим агентом, способствующим вытеснению из целлюлозных волокон молекул воды, которая выполняет функцию сокатализатора реакций модифицирования и деструкции целлюлозы. С разрушением водородных связей отрыв мелких целлюлозных частиц с уязвимой обезвоженной поверхности волокна, может происходить значительно легче. Это приводит к увеличению в образцах водорастворимой фракции, не вымываемой гексаном при промывке и сохраняемой при дальнейшем высушивании. 


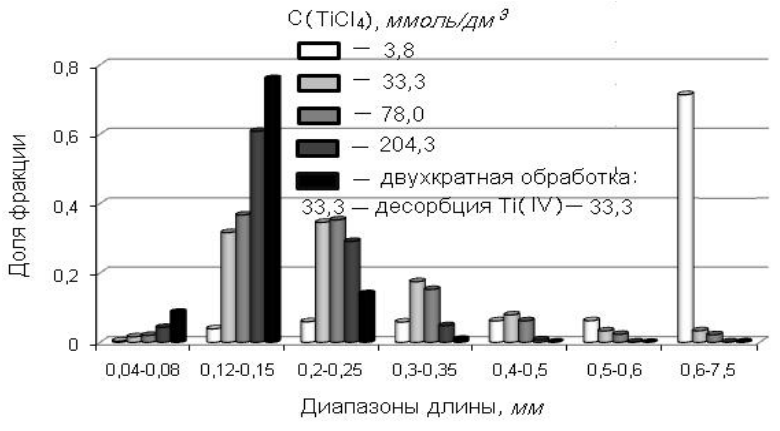

Рис. 2. Гистограмма фракционного распределения длины целлюлозных частиц образцов, полученных в результате обработки растворами $\mathrm{TiCl}_{4}$ различных концентраций

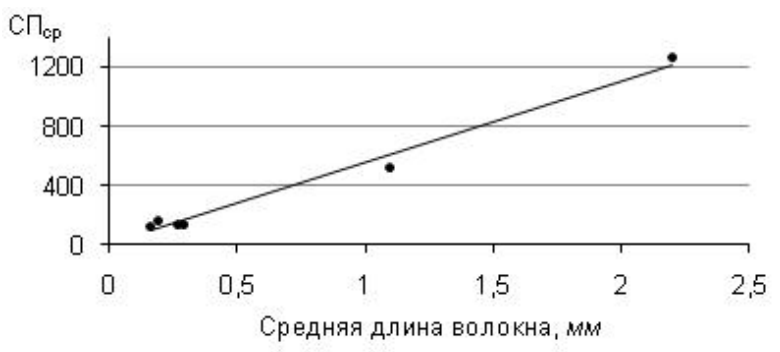

Рис. 4. Взаимосвязь величины СП длины целлюлозных частиц

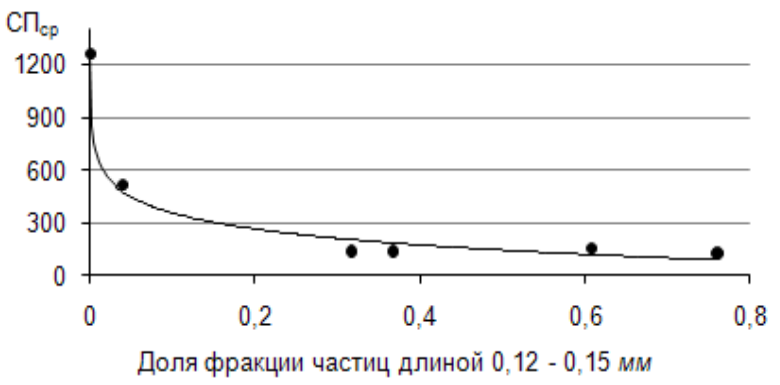

Рис. 3. Взаимосвязь величины СП ср и доли фракции целлюлозных частиц образцов 1-6 длиной $0,12 \div 0,15$ мм

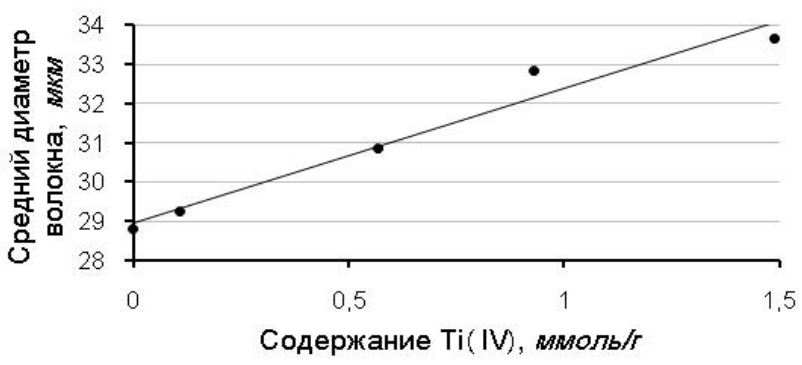

Рис. 5. Взаимосвязь среднего диаметра волокна и содержания Ti (IV) в образцах

Воздействие 10\%-ного водного раствора серной кислоты, применяемого для десорбции Ti (IV) из целлюлозных образцов, приводит к растворению титансодержащих групп и образовавшейся водорастворимой фракции (см. табл.), в результате чего целлюлозное волокно истончается. Так, на рисунке 6 видно, что для образца 3 средний диаметр волокна после однократной обработки в растворе $\mathrm{TiCl}_{4}$ концентрацией 33,3 ммоль/дм ${ }^{3}$ увеличился на 7\% (по отношению к таковому параметру исходной целлюлозы). Средний диаметр волокна образца 6, полученного после двукратной обработки целлюлозы в идентичных условиях с промежуточным этапом десорбции Ti (IV), характеризуется более низким значением по сравнению с тем же параметром вышеуказанного образца 3. Следует отметить, что содержание Ti (IV) на поверхности целлюлозных частиц образцов 3 и 6 (в виде адсорбированных титансодержащих групп) является приблизительно одинаковым как после однократной, так и после двукратной обработки.

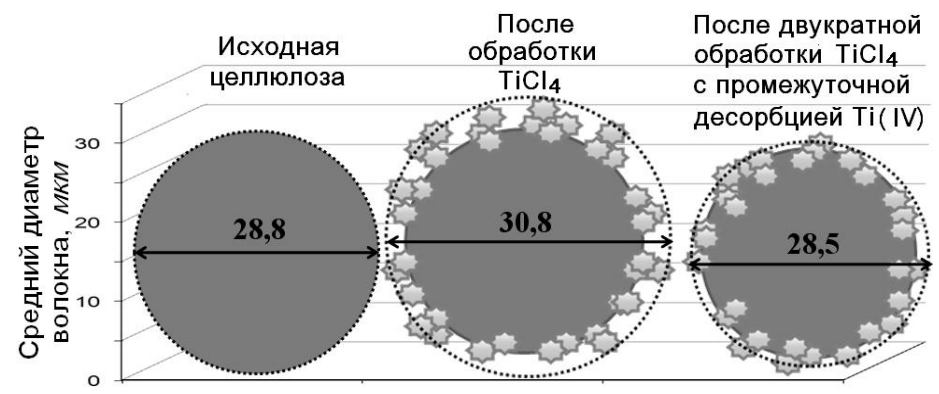

Рис. 6. Гистограмма изменения среднего диаметра целлюлозного волокна до и после обработок в растворе $\mathrm{TiCl}_{4}$ концентрацией 33,3 ммоль/дм ${ }^{3}$

\section{Выводы}

В результате обработки хвойной небеленой целлюлозы в растворах $\mathrm{TiCl}_{4}$ происходит изменение морфологических особенностей ее волокна, в частности диаметра и длины. Установлено, что получаемые образцы в зависимости от условий эксперимента в результате деструкции целлюлозного волокна характеризуются сравнительно узким фракционным распределением частиц по длине, средняя величина которой находится в интервале $0,16 \div 2,20$ мм. Выявлены линейные взаимосвязи средней длины частиц с величиной средней степени полимеризации $\left(\mathrm{CП}_{\mathrm{cp}}\right)$ целлюлозы в образцах и среднего диаметра частиц с содержанием в них Ti (IV). 


\section{Список литературы}

1. Zhang Z., Zhao Z.K. Solid acid and microwave-assisted hydrolysis of cellulose in ionic liquid // Carbohydrate Research. 2009. Vol. 344. Pp. 2069-2072.

2. Mansfield S.D., Meder R. Cellulose hydrolysis - the role of monocomponent cellulases in crystalline cellulose degradation // Cellulose. 2003. Vol. 10. Pp. 159-169.

3. Tian J., Wang J., Zhao S., Jiang C., Zhang X., Wang X. Hydrolysis of cellulose by the heteropoly acid $\mathrm{H}_{3} \mathrm{PW}_{12} \mathrm{O}_{40} / /$ Cellulose. 2010. Vol. 17. Pp. 587-594.

4. Азаров В.И., Буров А.В., Оболенская А.В. Химия древесины и синтетических полимеров. СПб., 1999. 628 с.

5. Алашкевич Ю.Д., Воронин И.А., Ковалев В.И., Решетова Н.С. Размол волокнистых полуфабрикатов нетрадиционным способом // Химия растительного сырья. 2009. №2. С. 165-168.

6. Афанасьев В.А. Механизмы активации молекул углеводов в условиях кислотно-основного катализа. Фрунзе, 1971. $138 \mathrm{c}$.

7. Sarybaeva R.I., Sultankulova A.S., Vasilikova T.V., Afanasiev V.A. Degradation of cellulose in the presence of Lewis acids // Cellulose chemistry and technology. 1991. Vol. 25. Pp. 199-210.

8. Sultankulova A.S., Sarybaeva R.I. Physicochemical and technological properties of powdery cellulose, obtained by the Lewis acid // Cellulose chemistry and technology. 1993. Vol. 27. Pp. 259-265.

9. Патент 2528261 (РФ). Способ получения порошковой целлюлозы / С.В. Фролова, Л.А. Кувшинова, А.В. Кучин. 2014.

10. Патент 2493169 (РФ). Способ получения титансодержащих целлюлозных материалов / С.В. Фролова, Л.А. Кувшинова, А.В. Кучин. 2013.

11. Кувшинова Л.А., Фролова С.В., Демин В.А. Физико-химические свойства хвойной небеленой целлюлозы с модифицированной тетрахлоридом титана поверхностью // Химия растительного сырья. 2014. №2. С. 21-28.

12. Hider S., Marchessault R.H. Studies on alcohol-modified transition metal polymerization catalysts. II. Interaction of $\mathrm{TiCl}_{4}$ with cellulose and model compounds // J. Polymer Sci. 1965. N11. Pp. 97-105.

13. Фролова С.В., Кувшинова Л.А., Бугаева А.Ю., Кучин А.В. Термический анализ порошковых целлюлоз полученных деструкцией сульфатной целлюлозы тетрахлоридом титана // Химия растительного сырья. 2011. №2. C. $43-46$.

14. Фролова С.В., Кувшинова Л.А., Рязанов М.А., Кучин А.В. Влияние тетрахлорида титана, применяемого для получения порошковой целлюлозы, на кислотно-основные свойства ее суспензий // Химия в интересах устойчивого развития. 2012. №2. С. 243-247.

15. Карякин Ю.В., Ангелов И.И. Чистые химические вещества. М., 1974. 408 с.

16. Фадеева В.И., Шеховцова Т.Н., Иванов В.И. Основы аналитической химии. М., 2001. 463 с.

17. Болотникова Л.С., Данилов С.Н., Самсонова Т.И. Метод определения вязкости и степени полимеризации целлюлозы // Журнал прикладной химии. 1966. Т. 39, №1. С. 179-180. 
Kuvshinova L.A. ${ }^{I^{*}}$, Manahova T.N. ${ }^{2}$ CHANGES OF MORPHOLOGICAL FEATURES OF CELLULOSE UNDER THE INFLUENCE OF TITANIUM TETRACHLORIDE

${ }^{I}$ Institute of Chemistry of Komi Scientific Centre of the Ural Branch of the Russian Academy of Sciences, Pervomaiskaya st. 48, Syktyvkar, 167982 (Russia), e-mail: fragl74@mail.ru

${ }^{2}$ Severny (Arctic) Federal University M.V. Lomonosov, st. Naberezhnaia Severnoi Dviny, 17, Arkhangelsk, 163002

(Russia),e-mail: tatiankaya17@yandex.ru

Shown changing morphological characteristics of cellulose under the influence solutions TiCl4 by automatic device Fiber Tester L\&W. Established that, the cellulose particles of samples may be different among themselves in the average length over a wide range $2,2 \div 0,16 \mathrm{~mm}$, depending on the experimental conditions. Interrelationships of sizes of average length and of average diameter of the particle with an average degree of polymerization (PDav) cellulose in samples and with the content of Ti (IV) identified.

Keywords: cellulose, powdered cellulose, titanium tetrachloride, analyzer fiber, length and diameter of fiber.

\section{References}

1. Zhang Z., Zhao Z.K. Carbohydrate Research, 2009, vol. 344, pp. 2069-2072.

2. Mansfield S.D., Meder R. Cellulose, 2003, vol. 10, pp. 159-169.

3. Tian J., Wang J., Zhao S., Jiang C., Zhang X., Wang X. Cellulose, 2010, vol. 17, pp. 587-594.

4. Azarov V.I., Burov A.V., Obolenskaya A.V. Khimiia drevesiny i sinteticheskih polimerov. [Chemistry of wood and synthetic polymers]. St. Petersburg, 1999, 628 p. (in Russ.).

5. Alashkevich U.D. Khimiia rastitel'nogo syr'ia, 2009, no. 2, pp. 165-168. (in Russ.).

6. Afanas'ev V.A. Mekhanizmy aktivacii molekul uglevodov v usloviyakh kislotno-osnovnogo kataliza [Mechanisms of the activation of carbohydrates in the acid-base catalysis]. Frunze, 1971, 138 p. (in Russ.).

7. Sarybaeva R.I., Sultankulova A.S., Vasilikova T.V., Afanasiev V.A. Cellulose chemistry and technology, 1991, vol. 25, pp. 199-210.

8. Sultankulova A.S., Sarybaeva R.I. Cellulose chemistry and technology, 1993, vol. 27, pp. 259-265.

9. Patent 2528261 (RU). 2014. (in Russ.).

10. Patent 2493169 (RU). 2013. (in Russ.).

11. Kuvshinova L.A., Frolova S.V., Demin V.A. Khimiia rastitel'nogo syria, 2014, no. 2, pp. 21-28. (in Russ.).

12. Hider S., Marchessault R.H. J. Polymer Sci, 1965, vol. 11, pp. 97-105.

13. Frolova S.V., Kuvshinova L.A., Bugaeva A.Y., Kutchin A.V. Khimiia rastitel'nogo syr'ia, 2011, no. 2, pp. $43-46$. (in Russ.).

14. Frolova S.V., Kuvshinova L.A., Ryazanov M.A., Kutchin A.V. Khimiia v interesah ustoy'chivogo razvitiia, 2012, no. 2, pp. 243-247. (in Russ.).

15. Karyakin J.V., Angels I.I. Chistye khimicheskie veschestva. [Clean chemical substances]. Moskow, 1974, 408 p. (in Russ.).

16. Fadeeva V.I., Shekhovtsova T.N., Ivanov V.I. Osnovy analiticheskoy khimi. [Fundamentals of analytical chemistry] Moskow, 2001, 463 p. (in Russ.).

17. Bolotnikova L.S., Danilov S.N., Samsonova T.I. Jurnal prikladnoy khimii, 1966, vol. 39, no. 1, pp. 179-180. (in Russ.).

Received July 29, 2013

\footnotetext{
* Corresponding author.
} 